\title{
Approach to Prostate Cancer Treatment in Elderly Patients with High Comorbidity
}

\author{
(• Hasan Hüseyin Tavukçu' ${ }^{1}$ (๑) Mustafa Kaplan² \\ 1 University of Health Sciences Turkey, Sultan 2. Abdülhamid Han Training and Research Hospital, Clinic of Urology, Istanbul, Turkey \\ 2 Vega Hospital, Clinic of Urology, Tekirdağ, Turkey
}

\begin{abstract}
The incidence of prostate cancer increases with age, and elderly patients often have other accompanying diseases. The most important clinical prediction for deciding on curative treatment in localized prostate cancer treatment is the 10-year survival status of the patient. In advanced prostate cancers, treatment is usually decided according to the comorbidity and age of the patients. Guidelines and consensus reports recommend that patients' general health status should be determined by validated health status screening forms in deciding on treatment for prostate cancer in elderly patients. After evaluating the health status, the treatment options recommended by the guidelines should be presented to the patients according to the risk group of the patient and the treatability of the existing diseases, regardless of their age. Patients who are found to be healthy as a result of the evaluation should be included in the standard treatment applied to non-elderly patients. For patients who are frail but have treatable disease, standard treatment is recommended after correction or improvement of comorbidities. Supportive treatment and adapted treatment options should be offered to the patients who are in a frail state.
\end{abstract}

Keywords: Comorbidity, prostate cancer, health status, elderly

\section{Introduction}

Life expectancy is increasing in the world and in our country, so the majority of the patients who encounter with prostate cancer (PC) are older patients. The median age of patients diagnosed as having prostate cancer is 66 in the world. Mostly metastatic PC is diagnosed at a later age and the median age of death is reported as 80 (1). The proportion of patients over the age of 65 who will be diagnosed as having PC in the United States in 2030 is estimated to be $70 \%$ (2). There is a similar increase in expectation for Europe (3). Early and late PC treatment in elderly patients will increase gradually in the coming decades and will become a common public health problem (4).

In the United States of America, curative treatment is applied to only $41 \%$ of patients in the intermediate and advanced risk group in men over 75 years of age, while curative treatment is applied to $88 \%$ of patients aged 65-74 (5). Life expectancy of more than 10 years in treatment of localized PC is a key clinical factor for benefit from local treatment. This is due to the impact of existing comorbidities on life years. Studies report that the presence of comorbidity is a more important factor than age in predicting death from localized PC (6). At the end of a decade, most patients with a Charlson comorbidity index $>2$ die due to comorbid diseases, regardless of age or cancer aggressiveness.

In this review, comorbidity-weighted recommendations and treatment approaches in the treatment approach of elderly patients with PC and high comorbidity will be reviewed.

\section{History}

The International Society for Geriatric Oncology (SIOG) has published several different guidelines on the management of PC in elderly patients since $2010(7,8,9,10)$. Although none of these literature reviews are systematic, they are all reported as consensus reports that include multidisciplinary expert opinions (4). Their purpose can be basically expressed as defining the "elderly frail" patient group in urology and oncology. These guidelines have accepted patients over 70 years of age as the elderly.

In the first SIOG article, the most important geriatric factors such as dependency, comorbidity, and nutritional status were discussed (7). The most important result was that the treatment should be made not according to chronological age, but should be made according to different tools that scanned the general 
health status and according to methods such as "comprehensive geriatric assessment" (CGA) for detailed examination. This working group published the first SIOG recommendations in the same year (8). In the updated guideline in 2014 (10), they suggested that simple geriatric evaluation with Geriatric 8 (G8) health status screening tool (11) or CGA in geriatric clinics in some patients should be performed to identify patients and distinguish those who would benefit from treatment. The 2017 update contained 2 important perspectives: Screening the cognitive status disorder (with the Mini $\mathrm{COG}^{\mathrm{TM}}$ tool) and the introduction of early palliative care (9).

The second important date was the full adoption of the SIOG guidelines by the European Association of Urology (EAU) in 2017 (The EAU/ESTRO/SIOG Guidelines) (12). In 2018, the same working group made a new update. This update is very comprehensive and includes surgery, minimally invasive treatments and follow-up, radiotherapy (RT) and brachytherapy, health status assessment, and geriatric oncological conditions in low-middle-income countries (4) (Table 1).

\section{The Assessment of General Health Status}

The basic approach in PC is to decide according to the biological age and current general health status rather than the chronological age of the patient (12). For this purpose, a standard clinical evaluation and the Eastern Cooperative Oncology Group Performance score are generally used in the clinic to distinguish healthy individuals from unhealthy individuals (13) (Table 2). CGA can be used to define health status and predict treatment risks (14). The SIOG strongly recommends that CGA be included in the treatment plan for elderly patients (15). However, CGA will be applied with difficulty as it will be both costly and time consuming for clinicians who do not have a geriatric clinic and do not have sufficient experience in this field. Therefore, it may not be necessary to fill CGA in all elderly patients. It will be more appropriate to determine the patients who will require advanced geriatric examination. If necessary, CGA should be performed after geriatric screening and examinations. Since the health status of elderly patients may change over time, evaluations should be repeated at every step (4).

\section{Geriatric Scanning}

The G8 screening is the most common and short-lasting screening method to identify patients who will require geriatric evaluation $(11,16)$. G8 is an easy assessment method that can be completed in 4 minutes (Tables 3 and 4). It has been specially developed for patients with cancer and includes nutritional status, body mass index, mobility, neuropsychiatric problems, multiple drug use, self-health status and age. The highest score is 17 and score $\leq 14$ is considered abnormal. The use of G8 screening is also recommended by EAU guidelines (17). The 2017 SIOG guidelines recommends Mini-COG ${ }^{\mathrm{TM}}$ to evaluate cognitive functions together with the G8 screening (9). Mini-COG ${ }^{\mathrm{TM}}$ has been determined to be the most compatible test with Mini Mental State Examination among 10 different cognitive screening tests $(18,19)$. When the result is abnormal, further investigations should be performed to provide a complete cognitive assessment of the patient. Mini-COG ${ }^{\mathrm{TM}}$ consists of three-word- recall test and clock drawing test and can be completed in 5 minutes. Values $\leq 3 / 5$ indicate that the patient needs to be guided for fully evaluation of potential dementia (4).

\section{Comprehensive Geriatric Assessment (CGA)}

CGA should be applied to patients with G8 score $\leq 14 / 17$. CGA, which is the gold standard for geriatric health status assessment, includes a comprehensive, interdisciplinary diagnostic process to determine the care needs of frail elderly patients, plan care and improve outcomes $(20,21)$. CGA includes functional status, fatigue, cognitive status, comorbidity, mental status, social support, nutrition, and geriatric syndromes (22). In elderly patients with cancer, CGA can predict survival and treatmentrelated adverse effects, influence treatment choice, and reflect patients' values and treatment goals, as well as their decisionmaking capacity (15).

\section{The Geriatric Assessment}

It may be necessary to conduct a relevant multidisciplinary study for each problem detected in CGA. It is recommended that the multidisciplinary team includes nurses, psychologists, dieticians, social workers, pharmacists and other relevant therapists (4). However, although CGA is recommended for all patients with cancer, it has been reported that its clinical application has been investigated in very few studies $(23,24,25)$. Many studies are currently ongoing, and higher level of evidence will be reported with their results $(4,26)$.

As the number of elderly patients with cancer is increasing all over the world, the need for a healthcare team trained in geriatrics will indirectly increase. This team will need electronic evaluation forms that can be used more quickly to inquire about the health status of elderly patients (27). There are 3 electronic CGA forms available today $(28,29,30)$. Although it is stated that these forms can be easily used even in the most crowded oncology clinics, they need to be supported by larger series (4). The latest American Society of Clinical Oncology (ASCO) guidelines recommend integrating CGA into daily practice in elderly patients receiving chemotherapy, and recommend the use of a validated tool listed in ePrognosis to estimate non-cancer life expectancy in the adjuvant and treatment setting $(31,32)$. Schonberg and Lee indexes are also well validated usable forms. These indices include both comorbidities and functional status (4). The ASCO guidelines recommended the use of different screening tools, but especially the use of CGA, in addition to screening tests such as G8 and the geriatric assessment (31).

In summary, when the ASCO guidelines recommendations are adapted to SIOG guidelines;

- First, elderly patients with PC should be screened using the G8 and Mini-COG ${ }^{\mathrm{TM}}$.

- Estimated non-cancer survival should be determined using ePrognosis in early stage PC, especially Shonberg and Lee indexes contribute to decision making. 
Tavukçu and Kaplan. Prostate Cancer in Elderly with Comorbidities

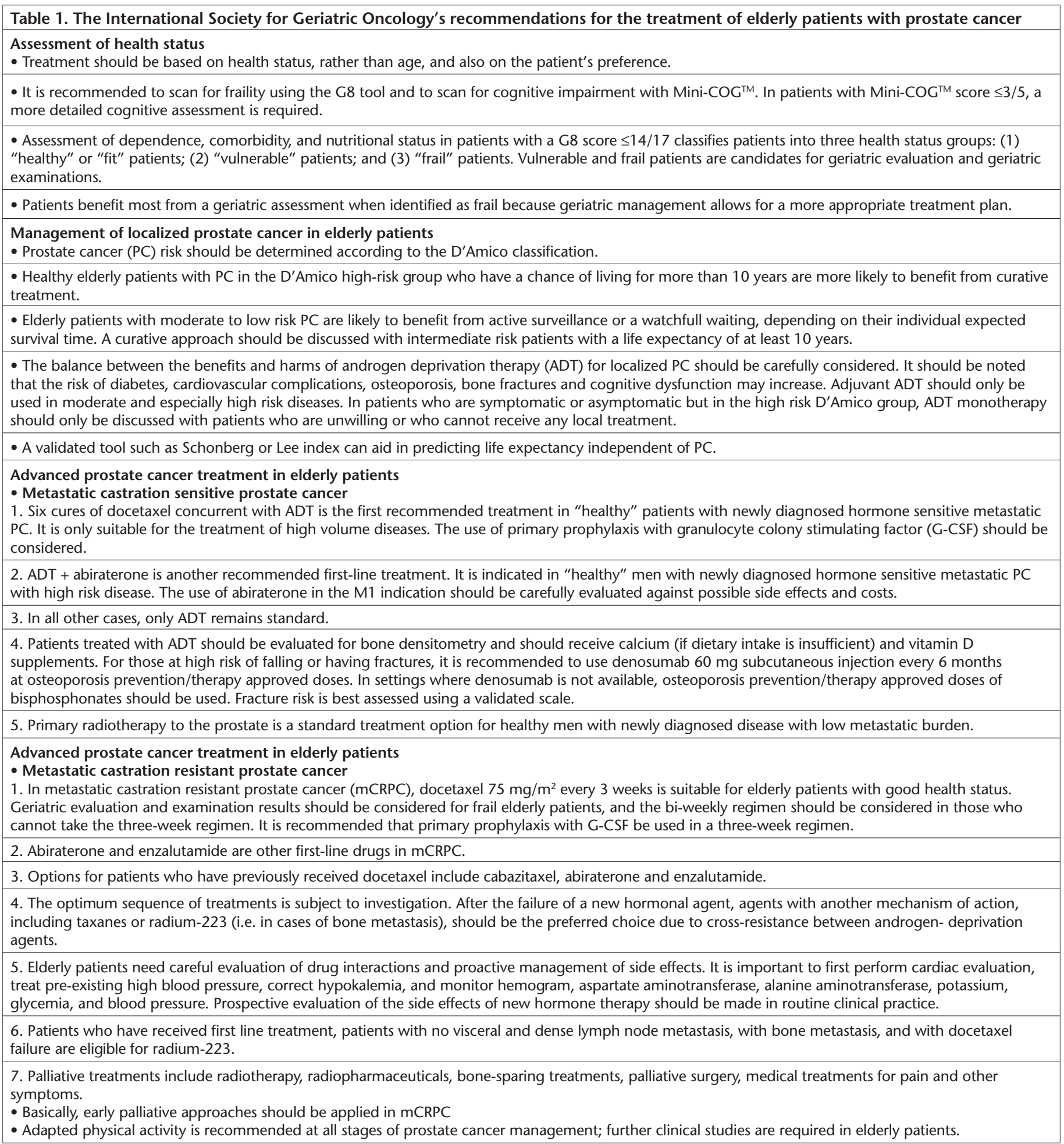

- The use of a fraility index suggested by the geriatric assessment or a similar tool predicts mortality and classifies elderly patients into healthy, vulnerable or fragile groups. The SIOG working group decided to use the health status category in 2014. Accordingly; (1) Healthy elderly is defined as an elderly with a G8 screening score of $>14 / 17$, without comorbidity, dependency, malnutrition or impairment in cognitive status, (2) Vulnerable elderly is defined as an elderly who is unable to perform some daily activities, with moderate malnutrition or comorbidity, and (3) Frail elderly are patients who are debilitated, dependent, 


\begin{tabular}{|c|c|c|c|}
\hline Karnofsky status & $\begin{array}{l}\text { Karnofsky } \\
\text { grade }\end{array}$ & $\begin{array}{l}\text { ECOG } \\
\text { score }\end{array}$ & ECOG status \\
\hline $\begin{array}{l}\text { The patient can continue his/her normal activity, there may be several } \\
\text { symptoms or signs of the disease. }\end{array}$ & 90 & 1 & $\begin{array}{l}\text { Can continue his/her daily life with tolerable tumor } \\
\text { findings }\end{array}$ \\
\hline $\begin{array}{l}\text { The patient can take care of himself/herself and cannot do his/her normal } \\
\text { activity and job. }\end{array}$ & 70 & 2 & $\begin{array}{l}\text { Having disturbing tumor findings but spending more } \\
\text { than } 50 \% \text { of his/her time out of bed }\end{array}$ \\
\hline Patient can meet his/her needs, rarely needs help, needs some help & 60 & & \\
\hline Help and medical attention are often required. & 50 & 3 & $\begin{array}{l}\text { Severely ill and forced to stay bed-bound more than } \\
50 \% \text { of his/her time }\end{array}$ \\
\hline About to die & 10 & & \\
\hline Dead & 0 & 5 & Dead \\
\hline
\end{tabular}

\begin{tabular}{|c|c|c|}
\hline & Question & Answer (Score) \\
\hline A & $\begin{array}{l}\text { In the last } 3 \text { months, was } \\
\text { there digestive problems, } \\
\text { a decrease in appetite, and } \\
\text { a decrease in nutrition due } \\
\text { to chewing or swallowing } \\
\text { difficulties? }\end{array}$ & $\begin{array}{l}0=\text { severe decrease in nutrition } \\
1=\text { moderate decrease in nutrition } \\
2=\text { no decrease in nutrition }\end{array}$ \\
\hline B & $\begin{array}{l}\text { Was there any weight loss } \\
\text { in the last } 3 \text { months? }\end{array}$ & $\begin{array}{l}0=\text { More than } 3 \mathrm{~kg} \\
1=\text { Did not } \mathrm{know} \\
2=\text { Loss of } 1-3 \mathrm{~kg} \\
3=\text { No weight loss }\end{array}$ \\
\hline $\mathrm{C}$ & Mobility & $\begin{array}{l}0=\text { Dependent on bed or chair } \\
1=\text { Can get out of bed or chair, but } \\
\text { cannot go out } \\
2=\text { Can go out }\end{array}$ \\
\hline $\mathrm{E}$ & $\begin{array}{l}\text { Neuropsychological } \\
\text { problem? }\end{array}$ & $\begin{array}{l}0=\text { Severe dementia or depression } \\
1=\text { Mild dementia } \\
2=\text { No psychological problems }\end{array}$ \\
\hline $\mathrm{F}$ & Body mass index (BMI) & $\begin{array}{l}0=\mathrm{BMI}<19 \\
1=\mathrm{BMI} 19-21 \\
2=\mathrm{BMI} 21-23 \\
3=\mathrm{BMI} \geq 23\end{array}$ \\
\hline $\mathrm{H}$ & $\begin{array}{l}\text { Prescripted drug use less } \\
\text { than } 3\end{array}$ & $\begin{array}{l}0=\text { Yes } \\
1=\text { No }\end{array}$ \\
\hline$P$ & $\begin{array}{l}\text { How does the patient feel } \\
\text { when compared to other } \\
\text { people of the same age? }\end{array}$ & $\begin{array}{l}0.0=\text { Not good } \\
0.5=\text { Did not know } \\
1.0=\text { Same } \\
2.0=\text { Better }\end{array}$ \\
\hline & Age & $\begin{array}{l}0:>85 \\
1=80-85 \\
2=<80\end{array}$ \\
\hline & Total score & $0-17$ \\
\hline
\end{tabular}

unable to perform many daily activities, have severe comorbidity and severe malnutrition. Vulnerable and frail patients should be treated with detailed geriatric assessment (Figure 1).
Prostate Cancer Treatment in the Elderly and Patients with Comorbidity

\section{Localized Prostate Cancer - Active Monitoring}

In elderly patients with poor health status, surgical treatment provides a low rate of cancer-specific and overall survival advantage, however, with increasing age, side effects of surgery are more common. Elderly patients over the age of 65 and with poor health status have year gain with a better quality of life with active follow-up (33). Active surveillance or watchfull waiting can be applied to patients in the low risk group. However, the risk of dying from PC or any other concomitant cause should be carefully evaluated and active surveillance should be decided accordingly (34). Although there was no difference in terms of cancer-specific survival between radical prostatectomy (RP), RT and active surveillance groups at the end of the 10 years of the ProtecT study, the highest quality of life was reported in the active surveillance group. Of the population group of the study; $60 \%$ were low-risk group patients and $40 \%$ were medium-risk group patients (35).

\section{Localized Prostate Cancer-Radical Prostatectomy}

Although advanced PC and higher rates of cancer-specific mortality are observed in elderly patients, most of the causes of death are other accompanying diseases. Those with high-risk diseases actually constitute the group of patients who take or will take the most benefit from RP (36). There is no significant difference in terms of cancer-specific mortality in high-risk patients over 70 years of age or below who have undergone RP at the end of 10 years of follow-up (37). The benefit of surgery in terms of cancer-related death is higher than active surveillance in patients with localized PC under the age of 65 years. However, in elderly patients, RP reduces the risk of metastasis and the use of androgen deprivation therapy (ADT) (38). In another study, 


\begin{tabular}{|c|c|c|c|}
\hline $\begin{array}{l}\text { "Cumulative illness } \\
\text { rating scale-geriatric" } \\
\text { score }\end{array}$ & & & \\
\hline Name & Age & Date & Scorer \\
\hline \multicolumn{4}{|l|}{ Scores } \\
\hline 0 & & None & \\
\hline 1 & & $\begin{array}{l}\text { Mild (or past serious } \\
\text { health problem) }\end{array}$ & \\
\hline 2 & & $\begin{array}{l}\text { Moderate (moderately } \\
\text { significant disability, } \\
\text { requiring level } 1 \\
\text { treatment) }\end{array}$ & \\
\hline 3 & & $\begin{array}{l}\text { Severe (persistent marked } \\
\text { disability/uncontrolled } \\
\text { chronic illness) }\end{array}$ & \\
\hline 4 & & $\begin{array}{l}\text { Advanced severe (need for } \\
\text { immediate treatment/end- } \\
\text { stage organ failure/severe } \\
\text { functional impairment }\end{array}$ & \\
\hline & & Score: & \\
\hline \multicolumn{4}{|l|}{ Cardiac } \\
\hline \multicolumn{4}{|l|}{ Vascular } \\
\hline \multicolumn{4}{|l|}{ Respiratory } \\
\hline \multicolumn{4}{|l|}{$\begin{array}{l}\text { Eye, ear, nose, throat, } \\
\text { larynx }\end{array}$} \\
\hline \multicolumn{4}{|l|}{$\begin{array}{l}\text { Upper gastrointestinal } \\
\text { tract }\end{array}$} \\
\hline \multicolumn{4}{|l|}{$\begin{array}{l}\text { Lower gastrointestinal } \\
\text { tract }\end{array}$} \\
\hline \multicolumn{4}{|l|}{ Hepatic } \\
\hline \multicolumn{4}{|l|}{ Kidney } \\
\hline \multicolumn{4}{|l|}{ Genitourinary } \\
\hline \multicolumn{4}{|l|}{ Musculoskeletal system } \\
\hline \multicolumn{4}{|l|}{ Neurological } \\
\hline \multicolumn{4}{|l|}{ Endocrine/metabolic } \\
\hline \multicolumn{4}{|l|}{ Psychiatric } \\
\hline Total score & & & \\
\hline
\end{tabular}

RP (with adjuvant therapies) in high-risk disease resulted in cancer-specific survival rates of $91 \%$. Survival was reported as $95 \%$ if any of the risk factors [Gleason $>7,>T 2$, prostate-specific antigen (PSA) $>20 \mathrm{ng} / \mathrm{mL}]$, and $79 \%$ if all three were present (39). The risk of early complications after RP is associated with increased comorbidity compared to age. On the other hand, in the long term, the risk of urinary incontinence and erectile dysfunction is affected more by increasing age $(40,41,42)$.

\section{Localized Prostate Cancer-Radiotherapy}

With RT applied with the appropriate dose (>72 Gy) and technique, similar cancer control and treatment-related comorbidity rates with RP are achieved, regardless of age (43). Studies on RT using hypofractionated techniques in recent years give high biochemical control rates in all risk groups $(44,45,46,47,48)$. However, routine use of RT is not recommended in patients in the low risk group due to the increase in late complications $(4,48)$. In addition, although most of these studies involve patients over the age of 70, no specific results have been reported for these age groups, so definitive interpretations can not be made for the elderly group. Although dose escalation studies on brachytherapy have been widely conducted in recent years, age-specific results have not been reported as in hypofractionated techniques. In addition, the procedure requires anesthesia, although less side effect rates have been reported $(49,50,51,52,53,54)$. Administration of ADT together with RT increases the morbidity and mortality of preexisting heart disease in elderly patients. Patients with moderate and severe comorbidity can not obtain a significant life-year benefit from ADT with RT. However, it has been reported that high-risk patients with no or less comorbidity benefit from ADT (55). In the medium-risk patient group, the combination of short-term ADT and RT is recommended $(55,56)$.

\section{Localized Prostate Cancer-Minimally Invasive Treatments}

Minimally invasive-ablative therapies are still experimental and there is currently insufficient evidence to recommend them in elderly patients and patients with comorbidities.

\section{Localized Prostate Cancer-Androgen Deprivation Therapy}

ADT alone should not be used in patients with localized PC without metastasis. Patients with locally advanced disease (T3T4), PSA value higher than $50 \mathrm{ng} / \mathrm{mL}$ and PSA doubling time less than 12 months benefit from early $\operatorname{ADT}(57,58)$. In patients with high-risk diseases and in very frail patients, early initiation of ADT provides little overall survival advantage, but cancerspecific or symptom-free survival benefit has not been reported (57).

\section{Metastatic Prostate Cancer-Castration Sensitive Disease}

The first-line treatment is ADT in the elderly with hormone sensitive PC. Bone densitometry is recommended to determine basal bone mineral density in elderly patients and calcium and vitamin $D$ supplements are recommended to protect from osteoporosis (10).

In recent years, with the LATITUDE study, it has been reported that the addition of abiraterone to the ADT has significantly improved overall survival and radiological progression-free survival in the elderly (>70 years old) patient group. However, the strength of this study was found to be insufficient to make comments for patients $>75$ years old, and toxicity was not reported by special age groups $(59,60)$. In the STAMPEDE study, it was stated that the addition of abiraterone had a significant effect on overall survival in patients $>70$ years of age, and toxicity was found to be similar in this patient group compared to the group aged $<70$ years. However, patients with a history of cardiovascular disease were not included in this study (61).

With the early addition of docetaxel to ADT in the group of metastatic patients susceptible to castration, significantly higher overall survival rates were reported in CHAARTED, STAMPEDE and GETUG-15 studies, especially in high-volume disease [ $\geq 4$ bone metastases (one of them should be in spine bone) or pelvic bone and/or visceral metastasis] $(62,63,64)$. The addition of docetaxel was reported to be beneficial in patients younger 


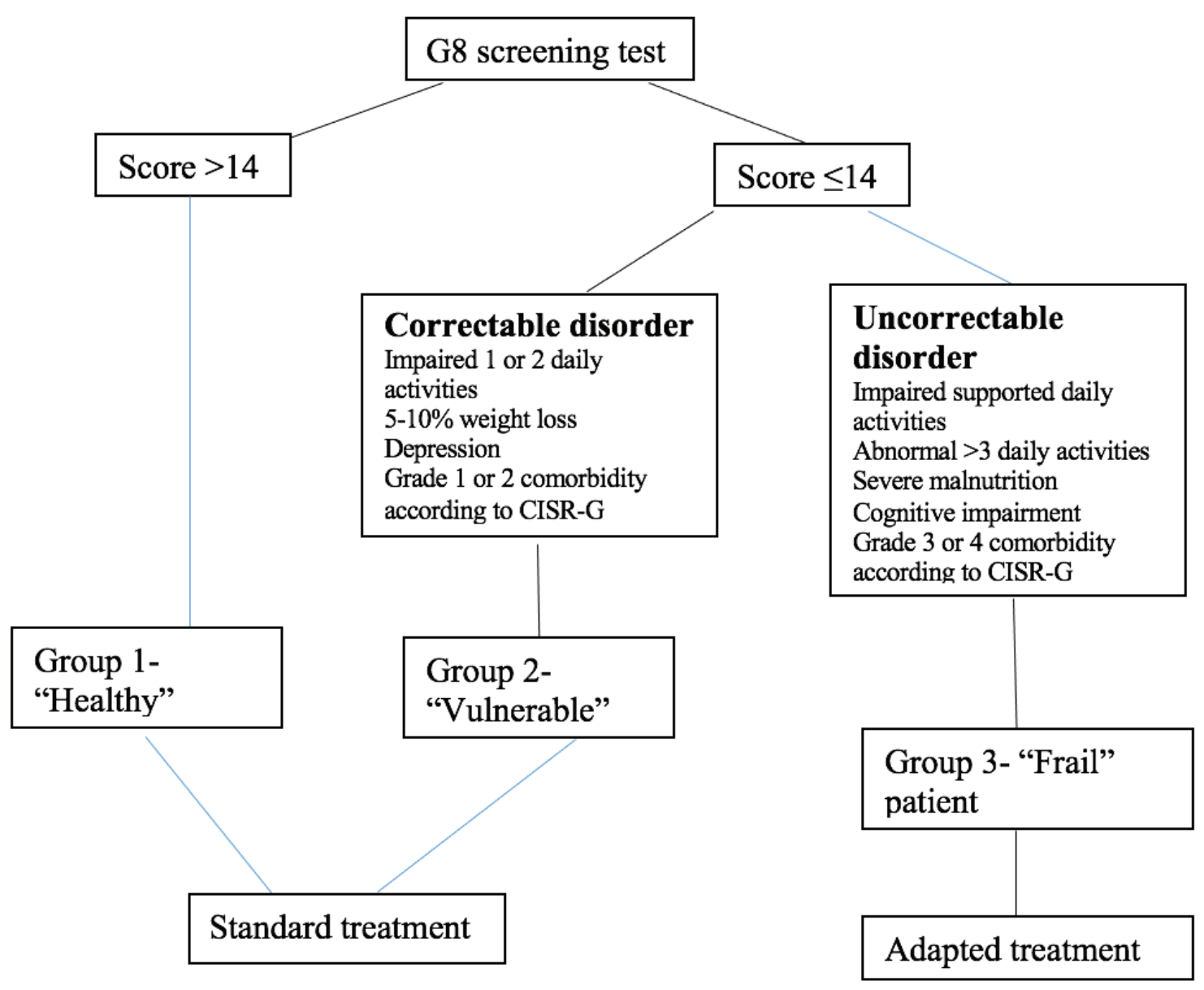

Figure 1. Decision tree in prostate cancer treatment according to health status

CIRS-G: Cumulative illness rating scale-geriatric

than 70 years of age or over (65). When evaluated as to whether there was a superiority between docetaxel and abiraterone, there was no difference in terms of the cancer-specific survival in the STAMPEDE study, while another metaanalysis reported that abiraterone was more effective in terms of overall survival $(66,67)$. However, since the rate of patients aged $>70$ years is $29 \%$ in these studies, this makes it difficult to interpret for the elderly patient group (4).

In the subsequent study of STAMPEDE, the groups with metastatic PC with and without primary RT were compared. In the subgroup analysis, it was reported that RT significantly contributed to overall survival in low volume metastatic patients (68). Primary RT was recommended as a standard in newly diagnosed metastatic PC with low metastatic load. However, the data in the study were not reported specific to age (4).

There is not enough information about the toxicity of abiraterone and docetaxel in the castration sensitive group and the elderly patient group (4). However, in docetaxel chemotherapy, especially in the elderly patient group, toxicity related to neutropenia was reported to be more frequent in castrationresistant patients (69).

Routine use of bisphosphonates or denosumab is not recommended to prevent skeletal complications in this patient group unless there is a suspicion of fracture or castrationresistant disease with bone metastases (70).

\section{Metastatic Prostate Cancer-Castration Resistant Disease}

The standard treatment for patients with castration-resistant metastatic PC and tolerable comorbidity is docetaxel chemotherapy, with similar results to younger patients (71). It was reported that in older and more frail patients, granulocyte colony stimulating factor prophylaxis with docetaxel could be given to protect the patient from febrile neutropenia, every 2 weeks (50 mg/kg for four weeks) or weekly instead of every 3 weeks (75 mg/kg) (72).

It was reported that the use of cabazitaxel as the first choice in castration-resistant disease was not superior to docetaxel (73). In the same study, overall survival was not found different, and toxicity was reported less with the dose of $20 \mathrm{mg} / \mathrm{m}^{2}$ than 25 $\mathrm{mg} / \mathrm{m}^{2}$. In second-line use, less toxicity was reported with the dose of $20 \mathrm{mg} / \mathrm{m}^{2}$ than $25 \mathrm{mg} / \mathrm{m}^{2}$ and a lower efficiency in terms of overall survival was not reported (74). It is recommended to prefer low doses in elderly patients as a better approach (4). In 
two different studies, it was suggested that administration of cabazitaxel at different doses and days would reduce toxicity rates and that the use of granulocyte colony stimulating factor could be applied concurrently with treatment $(75,76)$. In eligible patients cabazitaxel increases the life years in elderly patients receiving chemotherapy and susceptible to chemotherapy, similar to abiraterone acetate, enzalutamide, and sipuleucel-T $(77,78,79,80,81,82,83)$.

Radiopharmaceutical agents are generally less toxic than chemotherapy agents, so they may be more suitable for elderly patients. Studies with Ra223 have shown that hospitalization due to bone problems decreases and that they generally cause less toxicity as a result of its positive effects on bone lesions with early administration programs $(84,85,86,87)$. It has been reported that Ra223 can only be used with ADT and should not be used with other chemotherapeutic agents. Early results of the study of another new agent 177Lu-PSMA indicated that it was an effective treatment and its side effects were low (88).

In general, besides the side effects of ADT treatments, it has been reported that they are not generally associated with cognitive dysfunction as a result of the latest meta-analysis (89). Care should be taken in terms of the most important side effects of ADT, such as myocardial infarction, cerebrovascular disease, metabolic syndrome, diabetes, obesity, and dyslipidemia, and precautions should be taken, especially in elderly patients (90).

The general approach to PC in elderly patients, which is prepared based on the recommendations of the SIOG study group, is summarized in Table 1.

\section{Future Approaches}

There are many unknown questions about the treatment of metastatic PC, especially in elderly patients. However, the successive use of abiraterone and enzalutamide, regardless of age and health status, can develop a high rate of cross-resistance, on the other hand, taxanes are considered highly effective drugs that can be used easily after new hormonal treatments (4).

Although it has been reported that poly ADP-ribose polymerase-1 inhibitors such as olaparib and ipilimumab as immunotherapy do not have a distinctly different side effect profile in the elderly patient group, the results of new studies are expected for more accurate interpretations $(91,92)$.

\section{Conclusion}

The choice of treatment should be decided in elderly patients with PC according to their general health status. Age affects the treatment less than comorbidity, and general health status should be determined with a validated screening form such as G8 and comorbid disease assessment scales. Geriatric evaluation should be made in patients according to their existing comorbidities. The health status of the patient should be determined according to the biological age and current comorbidity, not the chronological age. The standard treatment recommended by the guideline according to the current PC stage should be given to the patients without comorbidities, and standard PC treatment should be given after the evaluation of vulnerable patients and the geriatric examination-recovery.
Only palliative and supportive treatments should be applied to elderly patients who are found to be frail.

\section{Acknowledgements}

Publication: The results of the study were not published in full or in part in form of abstracts.

Contribution: There is not any contributors who may not be listed as authors.

Conflict of Interest: No conflict of interest was declared by the authors.

Financial Disclosure: The authors declared that this study received no financial support.

\section{Ethics}

Peer-review: Externally peer-reviewed.

\section{Authorship Contributions}

Concept: H.H.T., Design: H.H.T., Data Collection and Processing: H.H.T., Analysis and Interpretation: H.H.T., Literature Search: M.K., Writing: H.H.T., M.K.

\section{References}

1. National Cancer Institute. SEERCancer Stat Facts: prostate cancer. 2018. Available from: https//seercancergouv/statfacts/html/ prosthtml2018. 2018.

2. Smith BD, Smith $G L$, Hurria A, et al. Future of cancer incidence in the United States: burdens upon an aging, changing nation. J Clin Oncol 2009;27:2758-2765.

3. Arnold M, Karim-Kos HE, Coebergh JW, et al. Recent trends in incidence of five common cancers in 26 European countries since 1988: analysis of the European Cancer Observatory. Eur J Cancer 2015;51:1164-1187.

4. Boyle HJ, Alibhai S, Decoster L, et al. Updated recommendations of the International Society of Geriatric Oncology on prostate cancer management in older patients. Eur J Cancer 2019;116:116-136.

5. Hamilton AS, Albertsen PC, Johnson TK, et al. Trends in the treatment of localized prostate cancer using supplemented cancer registry data. BJU Int 2011;107:576-584.

6. Albertsen PC, Moore DF, Shih W, et al. Impact of comorbidity on survival among men with localized prostate cancer. J Clin Oncol 2011;29:1335.

7. Droz JP, Balducci L, Bolla M, et al. Background for the proposal of SIOG guidelines for the management of prostate cancer in senior adults. Crit Rev Oncol Hematol 2010;73:68-91.

8. Droz JP, Balducci L, Bolla M, et al. Management of prostate cancer in older men: recommendations of a working group of the International Society of Geriatric Oncology. BJU Int 2010;106:462-469.

9. Droz JP, Albrand G, Gillessen S, et al. Management of prostate cancer in elderly patients: recommendations of a task force of the International Society of Geriatric Oncology. Eur Urol 2017;72:521-531.

10. Droz JP, Aapro M, Balducci L, et al. Management of prostate cancer in older patients: updated recommendations of a working group of the International Society of Geriatric Oncology. Lancet Oncol 2014;15:e404-e414. doi: 10.1016/S1470-2045(14)70018-X.

11. Soubeyran P, Bellera C, Goyard J, et al. Screening for vulnerability in older cancer patients: the ONCODAGE Prospective Multicenter Cohort Study. PLoS One 2014;9:e115060. doi: 10.1371/journal. pone.0115060.

12. Droz JP, Boyle H, Albrand G, et al. Role of geriatric oncologists in optimizing care of urological oncology patients. Eur Urol Focus 2017;3:385-394. 
13. Oken MM, Creech RH, Tormey DC, et al. Toxicity and response criteria of the Eastern Cooperative Oncology Group. Am J Clin Oncol 1982; 5:649-655.

14. Wedding U, Kodding D, Pientka L, et al. Physicians' judgement and comprehensive geriatric assessment (CGA) select different patients as fit for chemotherapy. Crit Rev Oncol Hematol 2007;64:1-9.

15. Wildiers $\mathrm{H}$, Heeren P, Puts $M$, et al. International Society of Geriatric Oncology consensus on geriatric assessment in older patients with cancer. J Clin Oncol 2014;32:2595-2603.

16. Decoster L, Van Puyvelde K, Mohile S, et al. Screening tools for multidimensional health problems warranting a geriatric assessment in older cancer patients: an update on SIOG recommendationsdagger. Ann Oncol 2015;26:288-300.

17. Mottet N B], Bolla M, Briers E, et al. EAU e ESTRO e ESUR e SIOG guidelines on prostate cancer. Part 1: screening, diagnosis, and local treatment with curative intent. Eur Urol 2017;71:618-629.

18. Tsoi KK, Chan JY, Hirai HW, et al. Cognitive Tests to Detect Dementia: A Systematic Review and Meta-analysis. JAMA Intern Med 2015;175:1450-1458.

19. Borson S, Scanlan JM, Chen P, Ganguli M. The Mini-Cog as a screen for dementia: validation in a population-based sample. J Am Geriatr Soc 2003;51:1451-1454.

20. Solomon DH. Geriatric assessment: methods for clinical decision making. JAMA 1988;259:2450-2452.

21. Reuben DB, Fishman LK, McNabney M, Wolde-Tsadik G. Looking inside the black box of comprehensive geriatric assessment: a classification system for problems, recommendations, and implementation strategies. J Am Geriatr Soc 1996;44:835-838.

22. Ellis G, Gardner M, Tsiachristas A, et al. Comprehensive geriatric assessment for older adults admitted to hospital. Cochrane Database Syst Rev 2017;9:CD006211. doi: 10.1002/14651858.CD006211. pub3

23. Puts MTE, Sattar S, Kulik M, et al. A randomized phase II trial of geriatric assessment and management for older cancer patients. Support Care Cancer 2018;26:109-117.

24. Schmidt H, Boese S, Lampe K, et al. Trans sectoral care of geriatric cancer patients based on comprehensive geriatric assessment and patient-reported quality of life - Results of a multicenter study to develop and pilot test a patient-centered interdisciplinary care concept for geriatric oncology patients (PIVOG). J Geriatr Oncol 2017;8:262-270.

25. Magnuson A, Lemelman T, Pandya, et al. Geriatric assessment with management intervention in older adults with cancer: a randomized pilot study. Support Care Cancer 2018;26:605-613.

26. $\mathrm{NCl}$ clinical trials. 2018. https://ClinicaltrialsGouv/Ct2/ Results?Terms=cancer+and+ geriatric assessment\&search.

27. Kalsi T, Babic-Illman G, Ross PJ, et al. The impact of comprehensive geriatric assessment interventions on tolerance to chemotherapy in older people. Br J Cancer 2015;112:1435-1444.

28. McCleary NJ, Wigler D, Berry D, et al. Feasibility of computer-based self-administered cancer-specific geriatric assessment in older patients with gastrointestinal malignancy. Oncologist 2013;18:64-72.

29. Hurria A, Akiba C, Kim J, et al. Reliability, validity, and feasibility of a computer-based geriatric assessment for older adults with cancer. J Oncol Pract 2016;12:e1025-e1034. doi: 10.1200/JOP.2016.013136.

30. Shahrokni A, Tin A, Downey RJ, et al. Electronic Rapid Fitness Assessment: A Novel Tool for Preoperative Evaluation of the Geriatric Oncology Patient. J Natl Compr Canc Netw 2017;15:172-179.

31. Mohile SG, Dale W, Somerfield MR, Hurria A. Practical assessment and management of vulnerabilities in older patients receiving chemotherapy: ASCO guideline for geriatric oncology summary. J Oncol Pract 2018;14:442-446.

32. University of california eprognosis: electronic tools. 2018. https:// EprognosisUcsfEdu/IndexPhp.
33. Liu D, Lehmann HP, Frick KD, Carter HB. Active surveillance versus surgery for low risk prostate cancer: a clinical decision analysis. J Urol 2012;187:1241-1246.

34. Albertsen PC, Hanley JA, Fine J. 20-year outcomes following conservative management of clinically localized prostate cancer. JAMA 2005;293:2095-2101.

35. Hamdy FC, Donovan JL, Lane JA, et al. 10-Year outcomes after monitoring, surgery, or radiotherapy for localized prostate cancer. $\mathrm{N}$ Engl J Med 2016;375:1415-1424.

36. Scosyrev E, Messing EM, Mohile S, Golijanin D, Wu G. Prostate cancer in the elderly: frequency of advanced disease at presentation and disease-specific mortality. Cancer 2012;118:3062-3070.

37. Briganti A, Spahn M, Joniau S, et al. Impact of age and comorbidities on long-term survival of patients with high-risk prostate cancer treated with radical prostatectomy: a multi-institutional competingrisks analysis. Eur Urol 2013;63:693-701.

38. Bill-Axelson A, Holmberg L, Garmo H, et al. Radical prostatectomy or watchful waiting in early prostate cancer. $N$ Engl J Med 2014; 370:932-942.

39. Joniau S, Briganti A, Gontero P, et al. Stratification of high-risk prostate cancer into prognostic categories: a European multi-institutional study. Eur Urol 2015;67:157-164.

40. Begg CB, Riedel ER, Bach PB, et al. Variations in morbidity after radical prostatectomy. N Engl J Med 2002;346:1138-1144.

41. Stanford JL, Feng Z, Hamilton AS, et al. Urinary and sexual function after radical prostatectomy for clinically localized prostate cancer: the Prostate Cancer Outcomes Study. JAMA 2000;283:354-360.

42. Kundu SD, Roehl KA, Eggener SE, et al. Potency, continence and complications in 3,477 consecutive radical retropubic prostatectomies. J Urol 2004;172:2227-2231.

43. Kupelian PA, Elshaikh M, Reddy CA, et al. Comparison of the efficacy of local therapies for localized prostate cancer in the prostatespecific antigen era: a large single-institution experience with radical prostatectomy and external-beam radiotherapy. J Clin Oncol 2002;20:3376-3385.

44. Dearnaley D, Syndikus I, Mossop H, et al. Conventional versus hypofractionated high-dose intensity-modulated radiotherapy for prostate cancer: 5-year outcomes of the randomised, non-inferiority, phase 3 CHHiP trial. Lancet Oncol 2016;17:1047-1060.

45. Incrocci L, Wortel RC, Alemayehu WG, et al. Hypofractionated versus conventionally fractionated radiotherapy for patients with localised prostate cancer (HYPRO): final efficacy results from a randomised, multicentre, open-label, phase 3 trial. Lancet Oncol 2016;17:1061-1069.

46. Arcangeli G, Saracino B, Arcangeli S, et al. Moderate hypofractionation in high-risk, organ-confined prostate cancer: final results of a phase III randomized trial. J Clin Oncol 2017;35:1891-1897.

47. Catton CN, Lukka H, Gu CS, et al. Randomized trial of a hypofractionated radiation regimen for the treatment of localized prostate cancer. J Clin Oncol 2017;35:1884-1890.

48. Lee WR, Dignam JJ, Amin MB, et al. Randomized phase III noninferiority study comparing two radiotherapy fractionation schedules in patients with low-risk prostate cancer. J Clin Oncol 2016;34:2325-2332.

49. Shahid N, Loblaw A, Chung HT, et al. Long-term toxicity and health-related quality of life after single-fraction high dose rate brachytherapy boost and hypofractionated external beam radiotherapy for intermediate-risk prostate cancer. Clin Oncol (R Coll Radiol) 2017;29:412-420.

50. Joseph N, Taylor C, O'Hara C, et al. A combined single high-dose rate brachytherapy boost with hypofractionated external beam radiotherapy results in a high rate of biochemical disease free survival in localised intermediate and high risk prostate cancer patients. Radiother Oncol 2016;121:299-303. 
51. Morris W], Tyldesley S, Rodda S, et al. Androgen Suppression Combined with Elective Nodal and Dose Escalated Radiation Therapy (the ASCENDE-RT Trial): an analysis of survival endpoints for a randomized trial comparing a low-dose-rate brachytherapy boost to a dose-escalated external beam boost for high- and intermediate-risk prostate cancer. Int J Radiat Oncol Biol Phys 2017;98:275-285.

52. Rodda S, Tyldesley S, Morris WJ, et al. ASCENDE-RT: an analysis of treatment-related morbidity for a randomized trial comparing a lowdose-rate brachytherapy boost with a dose-escalated external beam boost for high- and intermediate-risk prostate cancer. Int J Radiat Oncol Biol Phys 2017;98:286-295.

53. Rodda S, Morris WJ, Hamm J, Duncan G. ASCENDE-RT: an analysis of health-related quality of life for a randomized trial comparing lowdose-rate brachytherapy boost with dose-escalated external beam boost for high- and intermediate-risk prostate cancer. Int J Radiat Oncol Biol Phys 2017;98:581-589.

54. Hoskin P, Rojas A, Ostler $P$, et al. Single-dose high-dose-rate brachytherapy compared to two and three fractions for locally advanced prostate cancer. Radiother Oncol 2017; 124:56-60.

55. D'Amico AV, Chen MH, Renshaw AA, et al. Androgen suppression and radiation vs radiation alone for prostate cancer: a randomized trial. JAMA 2008;299:289-295.

56. Jones CU, Hunt D, McGowan DG, et al. Radiotherapy and short-term androgen deprivation for localized prostate cancer. $N$ Engl J Med 2011;365:107-118.

57. Studer UE, Collette L, Whelan P, et al. Using PSA to guide timing of androgen deprivation in patients with TO-4 NO-2 M0 prostate cancer not suitable for local curative treatment (EORTC 30891). Eur Urol 2008; 53:941-949.

58. Studer UE, Whelan P, Albrecht W, et al. Immediate or deferred androgen deprivation for patients with prostate cancer not suitable for local treatment with curative intent: European Organisation for Research and Treatment of Cancer (EORTC) trial 30891. J Clin Oncol 2006;24:1868-1876.

59. Fizazi K, Tran N, Fein L, et al. Abiraterone plus prednisone in metastatic, castration-sensitive prostate cancer. N Engl J Med 2017;377:352-360.

60. Chi KN, Protheroe A, Rodriguez-Antolin A, et al. Patient-reported outcomes following abiraterone acetate plus prednisone added to androgen deprivation therapy in patients with newly diagnosed metastatic castration-naive prostate cancer (LATITUDE): an international, randomised phase 3 trial. Lancet Oncol 2018; 19:194-206.

61. James ND, de Bono JS, Spears MR, et al. Abiraterone for Prostate Cancer Not Previously Treated with Hormone Therapy. N Engl J Med 2017;377:338-351.

62. Kyriakopoulos CE, Chen YH, Carducci MA, et al. chemohormonal therapy in metastatic hormone-sensitive prostate cancer: long-term survival analysis of the randomized phase III E3805 CHAARTED trial. J Clin Oncol 2018;36:1080-1087.

63. Gravis G, Boher JM, Joly F, et al. Androgen Deprivation Therapy (ADT) plus docetaxel versus adt alone in metastatic non castrate prostate cancer: impact of metastatic burden and long-term survival analysis of the randomized phase 3 GETUG-AFU15 trial. Eur Urol 2016;70:256-262.

64. James ND, Sydes MR, Clarke NW, et al. Addition of docetaxel, zoledronic acid, or both to first-line long-term hormone therapy in prostate cancer (STAMPEDE): survival results from an adaptive, multiarm, multistage, platform randomised controlled trial. Lancet 2016;387:1163-1177.

65. Sweeney Cl, Chen YH, Carducci M, et al. Chemohormonal therapy in metastatic hormone-sensitive prostate cancer. N Engl J Med 2015;373:737-746.

66. Sydes MR, Spears MR, Mason MD, et al. Adding abiraterone or docetaxel to long-term hormone therapy for prostate cancer: directly randomised data from the STAMPEDE multi-arm, multi-stage platform protocol. Ann Oncol 2018;29:1235-1248.
67. Wallis CJD, Klaassen Z, Bhindi B, et al. Comparison of abiraterone acetate and docetaxel with androgen deprivation therapy in highrisk and metastatic hormone-naive prostate cancer: a systematic review and network meta-analysis. Eur Urol 2018;73:834-844.

68. Parker CC, James ND, Brawley CD, et al. Radiotherapy to the primary tumour for newly diagnosed, metastatic prostate cancer (STAMPEDE): a randomised controlled phase 3 trial. Lancet 2018;392:2353-2366.

69. Italiano A, Ortholan C, Oudard S, et al. Docetaxel-based chemotherapy in elderly patients (age 75 and older) with castrationresistant prostate cancer. Eur Urol 2009;55:1368-1375.

70. Aapro M, Saad F. Bone-modifying agents in the treatment of bone metastases in patients with advanced genitourinary malignancies: a focus on zoledronic acid. Ther Adv Urol 2012;4:85-101.

71. Berthold DR, Pond GR, Soban F, et al. Docetaxel plus prednisone or mitoxantrone plus prednisone for advanced prostate cancer: updated survival in the TAX 327 study. J Clin Oncol 2008;26:242-245.

72. Kellokumpu-Lehtinen PL, Harmenberg $U$, Joensuu T, et al. 2-Weekly versus 3-weekly docetaxel to treat castration-resistant advanced prostate cancer: a randomised, phase 3 trial. Lancet Oncol 2013;14:117-124.

73. Oudard S, Fizazi K, Sengelov L, et al. Cabazitaxel Versus Docetaxel As First-Line Therapy for Patients With Metastatic Castration-Resistant Prostate Cancer: A Randomized Phase III Trial-FIRSTANA. J Clin Oncol 2017;35:3189-3197.

74. Eisenberger M, Hardy-Bessard AC, Kim CS, et al. Phase III study comparing a reduced dose of cabazitaxel $(20 \mathrm{mg} / \mathrm{m}(2))$ and the currently approved dose $(25 \mathrm{mg} / \mathrm{m}(2))$ in postdocetaxel patients with metastatic castration-resistant prostate cancer-PROSELICA. J Clin Oncol 2017;35:3198-3206.

75. Climent MA, Perez-Valderrama B, Mellado B, et al. Weekly cabazitaxel plus prednisone is effective and less toxic for 'unfit' metastatic castration-resistant prostate cancer: Phase II Spanish Oncology Genitourinary Group (SOGUG) trial. Eur J Cancer 2017;87:30-37.

76. Hui MM, Clement Cl. Evaluation of the early to mid-term efficacy and safety of deep sclerectomy without an intrascleral spacer for open-angle glaucoma in an Australian population. J Curr Glaucoma Pract 2018;12:107-112.

77. Sternberg $\mathrm{CN}$, de Bono JS, Chi KN, et al. Improved outcomes in elderly patients with metastatic castration-resistant prostate cancer treated with the androgen receptor inhibitor enzalutamide: results from the phase III AFFIRM trial. Ann Oncol 2014;25:429-434.

78. De Bono JS, Logothetis CJ, Molina A, et al. Abiraterone and increased survival in metastatic prostate cancer. $N$ Eng J Med 2011;364:1995-2005.

79. Scher HI, Fizazi K, Saad F, et al. Increased survival with enzalutamide in prostate cancer after chemotherapy. $N$ Engl J Med 2012;367:1187-1197.

80. De Bono JS, Oudard S, Ozguroglu M, et al. Prednisone plus cabazitaxel or mitoxantrone for metastatic castration-resistant prostate cancer progressing after docetaxel treatment: a randomised open-label trial. Lancet 2010;376:1147-1154.

81. Fizazi K, Scher HI, Molina A, et al. Abiraterone acetate for treatment of metastatic castration-resistant prostate cancer: final overall survival analysis of the COU-AA-301 randomised, double-blind, placebocontrolled phase 3 study. Lancet Oncol 2012;13:983-992.

82. Kantoff PW, Higano CS, Shore ND, et al. Sipuleucel-T immunotherapy for castration-resistant prostate cancer. N Engl J Med 2010;363:411-422.

83. Bahl A, Oudard S, Tombal B, et al. Impact of cabazitaxel on 2-year survival and palliation of tumour-related pain in men with metastatic castration-resistant prostate cancer treated in the TROPIC trial. Ann Oncol 2013;24:2402-2428.

84. Prior JO, Gillessen S, Wirth M, et al. Radiopharmaceuticals in the elderly cancer patient: Practical considerations, with a focus on prostate cancer therapy: A position paper from the International Society of Geriatric Oncology Task Force. Eur J Cancer 2017;77:127-139. 
85. Parker C, Zhan L, Cislo P, et al. Effect of radium-223 dichloride (Ra223) on hospitalisation: An analysis from the phase 3 randomised Alpharadin in Symptomatic Prostate Cancer Patients (ALSYMPCA) trial. Eur J Cancer 2017;71:1-6.

86. Vogelzang NJ, Coleman RE, Michalski JM, et al. Hematologic Safety of Radium-223 Dichloride: Baseline Prognostic Factors Associated With Myelosuppression in the ALSYMPCA Trial. Clin Genitourin Cancer 2017; 15:42-52.

87. Dan TD, Eldredge-Hindy HB, Hoffman-Censits J, et al. Hematologic Toxicity of Concurrent Administration of Radium-223 and Next-generation Antiandrogen Therapies. Am J Clin Oncol 2017;40:342-347.

88. Brauer A, Grubert LS, Roll W, et al. (177) Lu-PSMA-617 radioligand therapy and outcome in patients with metastasized castration-resistant prostate cancer. Eur J Nucl Med Mol Imaging 2017;44:1663-1670.
89. Sun M, Cole AP, Hanna N, Mucci LA, et al. Cognitive Impairment in Men with Prostate Cancer Treated with Androgen Deprivation Therapy: A Systematic Review and Meta-Analysis. J Urol 2018;199:1417-1425.

90. Ahmadi H, Daneshmand S. Androgen deprivation therapy: evidencebased management of side effects. BJU Int 2013;111:543-548.

91. Mateo J, Carreira S, Sandhu S, Miranda S, et al. DNA-Repair Defects and Olaparib in Metastatic Prostate Cancer. N Engl J Med 2015;373:1697-1708.

92. Beer TM, Kwon ED, Drake CG, Fizazi K, et al. Randomized, DoubleBlind, Phase III Trial of Ipilimumab Versus Placebo in Asymptomatic or Minimally Symptomatic Patients With Metastatic ChemotherapyNaive Castration-Resistant Prostate Cancer. J Clin Oncol 2017;35:40-47. 